\title{
Serological investigation into the association between Streptococcus bovis and colonic cancer
}

\author{
R Darjee, A P Gibb
}

\begin{abstract}
Aims-To determine if there was an increase in antibody titre to Streptococcus bovis in patients with colonic cancer, and if this might be a useful marker of the presence for colonic cancer.

Methods-Serum samples from 16 patients and 16 age matched controls were tested by immunoblot and enzyme linked immunosorbent assay (ELISA) against antigen preparations from two strains of $S$ bovis and one strain of Enterococcus faecalis.

Results-No distinction between cancer patients and controls could be made using immunoblots. ELISA did show an increase in antibodies to $S$ bovis, but there was a greater increase in antibodies to $E$ faecalis. The increase in antibody titres was greatest with antigens which had been treated with periodate, and was therefore thought not to be caused by antibody to the shared group D carbohydrate antigen.

Conclusion-It may be possible to construct a test for the detection of colonic cancer based on the detection of antibody to $S$ bovis or $E$ faecalis, though considerable further development of this concept is required.
\end{abstract}

(f Clin Pathol 1993;46:1116-1119)

Streptococcus bovis bacteraemia (in many cases with endocarditis) is associated with colorectal tumours in $25 \%$ to $80 \%$ of cases. ${ }^{1-6} S$ bovis bacteraemia and endocarditis have also been reported in association with other tumours of the gastrointestinal tract and with nonneoplastic colonic lesions, but the association with colorectal tumours is stronger, and the finding of any form of $S$ bovis infection necessitates rigorous exclusion of colonic neoplasia. ${ }^{124}$

The mechanism underlying this association is not known, but may be due to a specific increase in the incidence of $S$ bovis bacteraemia derived from the gut in patients with colonic cancer. Colonic cancer is associated with a roughly five-fold increase in the faecal carriage rate of $S$ bovis, ${ }^{7}$ which may in part explain the increased incidence of bacteraemia with this organism. In patients with coincidental cardiac valve lesions bacteraemia could lead to endocarditis, but in most patients the bacteraemia would be transient and clinically silent.
Bacteraemia with $S$ bovis may therefore be more common than is realised in colorectal cancer, and if this is the case there might be an increase in antibodies to the organism. Detection of such an antibody response might be useful as a marker of colonic neoplasia.

We therefore set out to measure antibody to crude preparations of $S$ bovis in serum samples from patients with colonic cancer and age-matched controls, using immunoblots and ELISA. To distinguish a specific antibody response from non-specific increase in antibody to colonic bacteria we also measured antibody to Enterococcus faecalis and to a cocktail of Gram negative lipopolysaccharide core antigens. $S$ bovis and $E$ faecalis share the group D carbohydrate antigen (which is sensitive to periodate ${ }^{8}$ ) and preparations treated with periodate were therefore used in ELISA to aid the detection of antibodies to species specific protein antigens.

\section{Methods}

For most experiments we used NCTC 8133 ( $S$ bovis biotype I); 10b167 (a local blood culture isolate of $S$ bovis biotype II from a patient with endocarditis and colonic adenoma); and NCTC 10449 ( $E$ faecalis). Other strains were blood culture isolates. Identification and biotype of the $S$ bovis isolates was confirmed by the Streptococcus Reference Unit, Central Public Health Laboratory, Colindale, London. Bacteria were grown overnight at $37^{\circ} \mathrm{C}$ in Todd Hewitt broth (THB; Oxoid) in a shaking incubator, harvested by centrifugation at $3000 \times g$ for 10 minutes, washed, and resuspended in distilled water.

A positive control serum was obtained, during the course of treatment, from a patient with $S$ bovis endocarditis. Serum samples from 16 patients admitted for primary surgery for colonic cancer were collected, and age matched control sera were selected from samples which had been submitted to this department to be tested for rheumatoid factor and anti-nuclear factor and found to be negative for both. All sera were heat inactivated at $56^{\circ} \mathrm{C}$ for 30 minutes and stored at $-20^{\circ} \mathrm{C}$.

Mutanolysin preparations ${ }^{9}$ were made by mixing $100 \mu \mathrm{l}$ bacterial suspension (in distilled water with an optical density (OD) of 10 at $660 \mathrm{~nm}$ ) with $5 \mu \mathrm{l}$ mutanolysin solution (Sigma, $1000 \mathrm{U} / \mathrm{ml}$ in $0.1 \mathrm{M}$ HEPES, pH $7 \cdot 2), 5 \mu$ l sodium azide ( $0 \cdot 4 \%$ weight/volume) and $5 \mu \mathrm{l}$ phenylmethylsulphonyl fluoride $(0.02 \mathrm{M}$ in ethanol). The mixture was \\ Medical Microbiology, \\ Edinburgh
}


incubated at $37^{\circ} \mathrm{C}$ for 18 hours and stored at $-20^{\circ} \mathrm{C}$. French press extracts were made from the growth obtained in 1 litre THB, washed, and resuspended in $30 \mathrm{ml}$ phosphate buffered saline (PBS) $(0.05 \mathrm{M}$ sodium phosphate, $0 \cdot 15 \mathrm{M}$ sodium chloride, $\mathrm{pH} 7 \cdot 4$ ). The organisms were fragmented in an ice cooled cell at a pressure of 8000 to 9000 pounds a square inch, repeated until more than $80 \%$ breakage was achieved, as determined by phase-contrast microscopy. The supernatant fluid, after centrifugation at $10000 \times g$ for 10 minutes, was collected and the protein content measured. ${ }^{10}$

\section{IMMUNOBLOTS}

Antigen preparations were solubilised with an equal volume of sample buffer $(4 \%$ weight/volume sodium dodecyl sulphate, $20 \%$ volume/volume glycerol, $2 \%$ volume/volume 2-mercaptoethanol, $0.002 \%$ weight/volume bromophenol blue, $\mathrm{pH} 6.8$ ) at $100^{\circ} \mathrm{C}$ for 10 minutes. Proteins $(50 \mu \mathrm{g}$ protein or $20 \mu \mathrm{l}$ mutanolysin preparation per $5 \mathrm{~mm}$ track) were separated on $10 \%$ polyacrylamide gels ${ }^{11}$ and transferred to nitrocellulose membrane $(0.2 \mu \mathrm{m}$ pore size $) .{ }^{12}$ The nitrocellulose was then washed for 10 minutes in TRIS-buffered saline (TBS; $0.02 \mathrm{M}$ TRIS, $0.5 \mathrm{M}$ sodium chloride, $\mathrm{pH} 7.5$ ), then in 3\% (weight/volume) gelatin in TBS for 45 minutes, then incubated with serum diluted in $1 \%$ gelatin in TBS for 3 hours. The nitrocellulose was then rinsed in distilled water and washed twice in Tween $20 \quad(0.025 \%$ (volume/volume) in TBS), incubated for one hour with horseradish peroxidase anti-human IgG (Sigma, diluted one in 500 in $1 \%$ gelatin in TBS), rinsed, and washed in Tween as before, and developed over 30 minutes with horseradish peroxidase colour reagent (Bio-Rad).

ELISA

NUNC polysorb flat-bottomed eight-well strips were coated with $100 \mu \mathrm{l}$ a well of

Figure 1 Immunoblot of antigen preparations from seven isolates of $S$ bovis with serum from a patien being treated for $S$ bovis endocarditis. All antigens are mutanolysin preparations except for lane 1, a French press preparation. Strains used are (1 and 2): NCTC 8133; (3): 116275 (biotype 1); (4): 116172 (biotype II);(5): $10 b 167$ (biotype II); (6): 106160 (biotype II); (7): $11 b 45$ (biotype II); (8): $12 b 42$ biotype II, from the same patient as the serum).
French press antigen preparation $(40 \mu \mathrm{g}$ protein $/ \mathrm{ml}$ ) in $0.05 \mathrm{M}$ sodium carbonate, $0.02 \%$ weight/volume sodium azide, $\mathrm{pH} 9.6$ ), incubated at room temperature overnight. Wells were then washed four times with wash buffer $(0.05 \%$ volume/volume Tween 20 , $0.05 \%$ sodium azide in PBS) in a Dynatech plate washer, shaken dry, and stored at $-20^{\circ} \mathrm{C}$. To prepare periodate treated antigen, strips coated with French press extract were incubated with $100 \mu$ l a well of sodium periodate $(0.01 \mathrm{M}$ in PBS) for two hours at room temperature, then washed four times.

To perform antibody assays, $100 \mu \mathrm{l}$ of a one in 1000 dilution of serum in antibody diluent $(4 \%$ weight/volume polyethylene glycol, $0.5 \%$ weight/volume bovine serum albumin in wash buffer) was added to duplicate wells and incubated for 90 minutes at $37^{\circ} \mathrm{C}$. Plates were then washed four times and incubated for 90 minutes at $37^{\circ} \mathrm{C}$ with $100 \mu \mathrm{l}$ a well of alkaline phosphatase conjugated anti-human IgG (ICN) or IgM (MilesYeda) diluted 1 in 1000 in antibody diluent. Plates were again washed, $100 \mu \mathrm{l}$ a well of alkaline phosphatase substrate $(0.1 \%$ weight/volume $p$-nitrophenyl phosphate (Sigma) in $0.05 \mathrm{M}$ sodium carbonate, $1 \mathrm{mM}$ magnesium chloride, $\mathrm{pH} 9 \cdot 8$ ) added, incubated for 60 minutes at room temperature, and $O D$ measured at $405 \mathrm{~nm}$ using an Anthos plate reader with substraction of blank readings from wells with no added serum. All assays of IgG or IgM antibody to each antigen preparation were performed as a batch.

Anti-LPS core ELISA assays were performed by Dr GR Barclay using plates coated with equal molar quantities of rough LPS from $E$ coli $\mathrm{K} 12$, Klebsiella pneumoniae $\mathrm{M10b}$, Pseudomonas aeruginosa PAC605 and Salmonella typhimurium 878, complexed with polymyxin. ${ }^{13}$ Results were expressed as median units where 100 was the median value determined from assays on 1000 blood donor sera.

The approximate $95 \%$ confidence interval (CI) of median values was calculated, as described by Campbell and Gardner. ${ }^{14}$ All $p$ values are derived from Mann-Whitney two sample tests calculated using Epi Info (Georgia, USA; USD Incorporated). ${ }^{15}$

\section{Results}

IMMUNOBLOTS

Serum from the patient with $S$ bovis endocarditis reacted strongly in immunoblot with whole cell protein preparations from several $S$ bovis isolates, although the pattern of bands observed varied considerably among isolates (fig 1). Reactivity of comparable strength was also observed with an isolate of $S$ mitior (NCTC 10712) but not with individual blood culture isolates of $S$ morbillorum, $S$ sanguis, $S$ mutans, or $E$ faecalis (data not shown). For further experiments we chose to use the NCTC strains of $E$ faecalis and $S$ bovis, together with the local isolate of $S$ bovis (10b 167) which had reacted most strongly (fig 1 ). $\begin{array}{llllllll}1 & 2 & 3 & 4 & 5 & 6 & 7 & 8\end{array}$ 


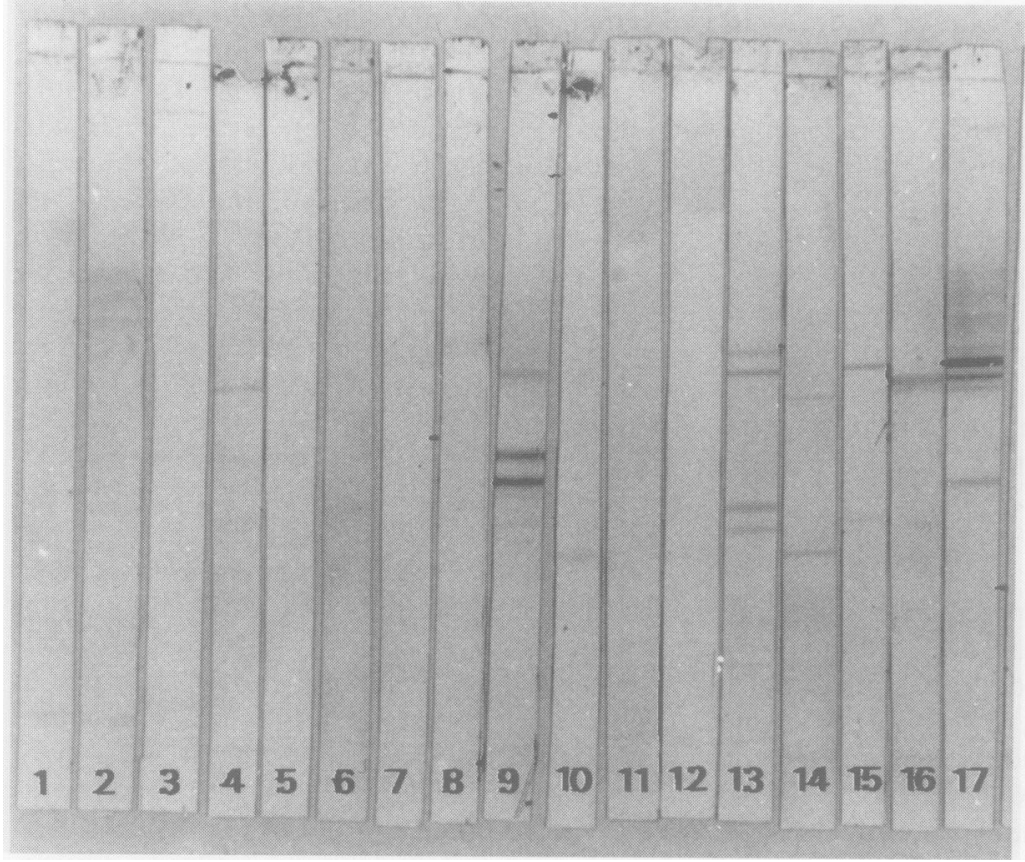

Figure 2 Immunoblot of sera from eight patients with colonic cancer (lanes 1-8), eight age matched controls (lanes 9-16), and one patient with $S$ bovis endocarditis (lane 17), against antigens prepared by French press method from $S$ bovis $10 b 167$.

Two batches of sera, each consisting of eight patients with colonic cancer, eight controls, and serum from the patient with endocarditis, were blotted against whole cell protein preparations from the selected $S$ bovis and $E$ faecalis strains, at a dilution of 1 in 20 . No consistent pattern was detected. Some sera from each group reacted with some bands from each organism, and no band could be identified with which the cancer sera regularly reacted. Figure 2 shows the results of one such inconclusive experiment. Blots were subsequently carried our with selected sera from each group at a range of higher dilutions ( 1 in 40,1 in 80 , and 1 in 160), but titres of reactivity could not be demonstrated by this approach (data not shown).

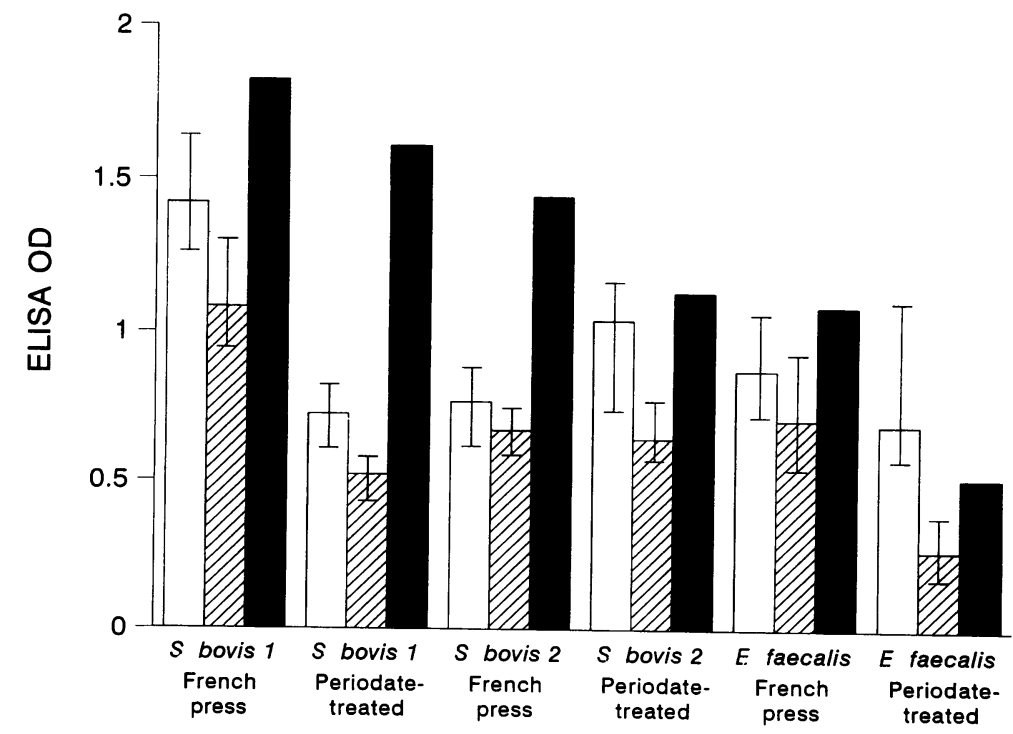

Figure 3 IgG antibody (ELISA OD) to six antigen preparations in 16 patients (open bars), 16 age matched controls (hatched bars), and one patient with $S$ bovis endocarditis. Bars represent median values and error bars represent the $95 \%$ confidence intervals of the median.
ELISA

Preliminary ELISA experiments were carried out with plates coated with French press extracts of $S$ bovis NCTC 8133 to determine suitable antigen coating concentration, serum dilution, and assay conditions to maximise the difference between the serum from the patient with $S$ bovis endocarditis and one of the sera from the control group which showed no bands in the immunoblot. Using these conditions, IgG and IgM ELISAs were performed against French press and periodate treated French press antigen preparations from each of the three selected bacterial strains.

Serum from the patient with endocarditis gave the highest reading in all of the assays with $S$ bovis antigens. In this serum sample the IgG antibody to periodate treated $S$ bovis antigen was almost as high as the antibody to native $S$ bovis antigen, suggesting that most of the antibody was directed against protein antigens (fig 3). The difference in IgG antibody to $E$ faecalis periodate treated and native antigens was much greater with this serum, suggesting that much of the antibody to $E$ faecalis in this serum was directed against carbohydrate antigens such as the group D antigen. Periodate treatment seemed, therefore, to have destroyed much of the common carbohydrate antigen but left the more species specific protein antigens. Periodate treatment also led to a substantial reduction in the detection of $\operatorname{IgM}$ antibody, which would be expected to be directed against carbohydrate antigens to a greater extent than is IgG.

The patients with colonic cancer had higher median IgG antibody titres to $S$ bovis and $E$ faecalis preparations than did the control patients (fig 3). This difference reached significance for both the $S$ bovis NCTC 8133 preparations $(p=0.001)$ and for the periodate treated preparations of $S$ bovis $10 \mathrm{~b} 167$ $(\mathrm{p}=0.0007)$ and $E$ faecalis $(\mathrm{p}<0.0001)$. The finding of increased IgG antibody to the periodate treated antigen from both species implies that the difference is not due to crossreactive antibody to group $\mathrm{D}$ carbohydrate. $\operatorname{IgM}$ antibody to the French press $S$ bovis 2 antigen was higher in the cancer group (median $0.87,95 \%$ CI 0.81 to 0.90 ) than in the controls (median $0.78,95 \%$ CI 0.76 to $0.83 ; \quad p=0.006)$. Significant differences among IgM antibody were not observed in any of the other assays.

Despite the differences among the groups there was a considerable overlap, and it would not have been possible to use any of these tests to predict usefully the presence of cancer. The best predictive values obtained were with the periodate treated $E$ faecalis antigen where 15 of the patients with cancer and three controls gave an OD above an arbitrary cutoff value of $0 \cdot 4$. This translates into a predictive value for positive results (true positives $\div$ (true positives + false positives)) of $83 \%$, and a predictive value for negative results (true negatives $\div$ (true negatives + false negatives)) of $93 \%$.

Antibody to polymyxin-LPS-core cocktail 
did not differ significantly between the cancer patients and controls. The IgG antibody titres was higher in the cancer patients (median $298,95 \%$ CI 166 to 459 ) than in the controls (median 220, 95\% CI 128 to 408 ). The IgM antibody titres was also a little higher in the cancer patients (median 131, 95\% CI 67 to 180 ) than the controls (median $125,95 \% \mathrm{CI}$ 101 to 202 ).

\section{Discussion}

Previous studies of antibody response to $S$ bovis and other streptococci and enterococci have found that antibody is detectable in endocarditis but not in either clinically insignificant bacteraemias ${ }^{16}{ }^{17}$ or colonic cancer. $^{3}$ These studies used immunoblotting, immunofluorescence, and crossed immunoelectrophoresis. We have also found that immunoblotting with whole cell proteins from $S$ bovis or $E$ faecalis was unable to distinguish between cancer patients and controls. All of these studies were limited by the use of relatively insensitive and non-quantitative methods.

In the more sensitive and quantitative ELISA we have shown an increase in IgG antibody to $S$ bovis in patients with colonic cancer, and also found an increase in IgG antibody titre to $E$ faecalis. The increase in IgG to $E$ faecalis did not seem to be due to antibody to shared carbohydrate antigens, and may reflect increased antibody to species specific protein antigens. If IgG antibody titres reflect the incidence of bacteraemia then this implies that both $S$ bovis and $E$ faecalis bacteraemias are more common in patients with colonic cancer. Cases of $E$ faecalis endocarditis have been associated with colonic cancer, but the association is much less strong than with $S$ bovis. ${ }^{18}$ This may be because $E$ faecalis endocarditis often results from a primary focus of infection at other sites, such as infection of the urinary tract, or perhaps because $S$ bovis bacteraemia is more likely to go on to cause endocarditis. It should be noted, however, that the antigen preparations used were crude and may have contained strain specific antigens or unrecognised common antigens which would confuse the interpretation of results. These questions might therefore be resolved by the use of pure antigens of known distribution among the relevant organisms.

The lack of any consistent difference in IgM antibody suggests that the increased immune stimulation in these patients has occurred over a long period of time, which is perhaps not surprising given the slow development of colonic cancer and the finding that $S$ bovis infection may be associated with the preclinical stages. ${ }^{1418}$ The lack of difference in antibody to LPS-core suggests that the increase in antibody titre to $S$ bovis and $E$ faecalis in patients with colonic cancer patients is not simply due to a non-specific increase in antibody to gut bacteria.
There is a need for a good screening test for colonic cancer, particularly a test which could detect early lesions. Detection of faecal occult blood is neither sensitive nor specific, while carcinoembryonic antigen is regularly detectable only in advanced disease. ${ }^{19}$ The results presented here suggest that it may be possible to develop a test to screen patients for the presence of colonic cancer by measuring IgG antibody titre to $S$ bovis or $E$ faecalis. Further investigation is required to identify antigens which would permit improved discrimination between the groups, and to determine whether antibody is also raised in other colonic diseases or in liver disease.

We are grateful to Dr A Miles for assistance in obtaining sera from cancer patients, to Mr D Morrison for identifying the $S$ bovis strains, and to Dr GR Barclay for performing the polymyxin-LPS-core antibody assays.

1 Klein RS, Catalano MT, Edberg SC, Casey JI, Steigbigel NH. Streptococcus bovis septicaemia and carcinoma of the colon. Ann Intern Med 1979;91:560-2.

2 Friedrich IA, Wormser GP, Gottfried EB. The asociation of recent Streptococcus bovis bacteraemia with colonic neoplasia. Mil Med 1982;147:584-5.

3 Kaplan $\mathrm{MH}$, Chmel H, Stephens A, et al. Humoral reactions in human endocarditis due to Streptococcus bovis: evidence for a common $\mathrm{S}$. bovis antigen. $\mathcal{F}$ Infect Dis 1983;148:266-74.

4 Beeching NJ, Christmas TI, Ellis-Pegler RB, Nicholson GI. Streptococcus bovis bacteraemia requires rigorous exclusion of colonic neoplasia and endocarditis. $Q F$ Med 1985;56:439-50.

5 Ruoff KL, Miller SI, Garner CV, Ferraro MJ, Calderwood SB. Bacteraemia with Streptococcus bovis and Streptococcus salivarius: clinical correlates of more accurate identification of isolates. $₹$ Clin Microbiol accurate identific

6 Zarkin BA, Lillemoe $\mathrm{KD}$, Cameron JL, Effron PN, Magnuson TH, Pitt HA. The triad of Streptococcus bovis bacteraemia, colonic pathology, and liver disease. Ann Surg 1990;211:786-92.

7 Klein RS, Recco RA, Catalano MT, Edberg SC, Casey JI, Steigbigel NH. Association of Streptococcus bovis with carcinoma of the colon. N Engl F Med 1977;297:800-2.

8 Wicken AJ, Baddiley J. Structure of intracellular teichoic acids from group D streptococci. Biochem $\mathcal{F}$ 1963;87: $54-62$.

9 Morris EJ, Ganeshkumar N, McBride C. Cell surface components of Streptococcus sanguis: relationship to aggregation, adherence, and hydrophobicity. $\mathcal{f}$ Bacteriol 985;164:255-62.

10 Lowry OM, Rosebrough NJ, Farr AL, Randall RJ. Protein measurement with the folin-phenol reagent. $\mathcal{F}$ Biol Chem 1951;193:265-75

11 Laemmli UK. Cleavage of structural proteins during assembly of the head protein of bacteriophage T4 Nature 1970;277:680-5.

12 Towbin H, Staehelin T, Gordon J. Electrophoretic transfer of proteins from polyacrylamide gels to nitrocellulose sheets: procedure and some applications. Proc Natl Acad Sci USA 1979;76:4350-4.

13 Scott BB, Barclay GR, Smith DGE, McLoughlin F Poxton IR. IgG antibodies to Gram-negative endotoxin in human sera. I. Lipopolysaccharide (LPS) crossreactivity due to antibodies to LPS core. Serodiagnost Immunother Infect Dis 1990;4:25-38.

14 Campbell MJ, Gardner MJ. Calculating confidence intervals for some non-parametric analyses. In: Gardner MJ, Altman DG, eds. Statistics with confidence. London: BMJ, 1989:71-9.

15 Dean AG, Dean JG, Burton AH, Dicker RC. Epi Info; Version 5. Stone Mountain, Georgia: USD Info; Version 5 .

16 Burnie JP, Holland M, Matthews RC, Lees W. Role of immunoblotting in the diagnosis of culture negative and immunoblotting in the diagnosis of culture negative and enterococcal

17 Shanson DC, Kirk N, Humphrey R. Clinical evaluation of a fluorescent antibody test for the serological diagnosis of streptococcal endocarditis. F Clin Pathol 1985;38 92-8.

18 Panwalker AP. Unusual infections associated with colonic cancer. Rev Infect Dis 1988;10:347-64.

19 Clark ML, Price AB, Williams CB. Tumours of the gastrointestinal tract. In: Weatherall DJ, Ledingham JGG, Warrell DA, eds. Oxford textbook of medicine. 2nd edn Oxford: Oxford University Press, 1987:146-58. 
brief descriptions of geographical distribution, morphology, and life cycle.

Section 2 contains over 250 colour photographs covering a wide range of parasite morphology, pathology (including stained sections), and clinical pictures with captions on the facing page. Although the overall quality of the photographs is excellent, I was disappointed to see a lack of size markers on all but a handful. In the clinical laboratory size is of vital importance for identifying ova and cysts.

The third section contains black and white electron micrographs, radiographs, and other illustrations, separated from the colour section for reasons of economy. This does not detract from the atlas in any way, and indeed some of the scanning electron microscopic images are quite breathtaking. I would, however, like to have seen some indication of size on the photographs.

This atlas has a spacious and orderly feel to it, and I am impressed by the overall quality. Clinical microbiologists, particularly those in training, will find it useful.

Atlas of Ovarian Tumors. L Deligdisch, A Altchek, CJ Cohen. (Pp 182; £94.) Igaku-Shoin. 1994. ISBN 0-89640-240-1.

This sumptuously produced atlas is subdivided into two main sections with three chapters devoted to "clinical aspects" and seven chapters allocated to "pathology". This strategy may be convenient in a multiauthor text, but it has resulted in a clinical section which is pathologically naive and a pathological section impoverished by the paucity of clinicopathological correlation.

The wide-ranging introductory chapter, which covers epidemiology, genetics, molecular biology, early diagnosis, and screening for ovarian cancer, provides a useful overview of the subject, although the emphasis placed on ultrasonography is excessive. The two ensuing chapters, both rather lengthy and repetitive, are devoted to management of ovarian carcinoma and nonepithelial tumours, respectively.

The pathology section comprises four chapters devoted to primary epithelial neoplasms including a whole chapter on the interesting but controversial subject of ovarian intraepithelial neoplasia. Other chapters deal with sex cord-stromal tumours, germ cell tumours, and metastatic tumours. This section is well illustrated with adequate photomicrographs and gross photographs of excellent quality. However, many entities are skimpily and uncritically described with no attempt to evaluate the taxonomic overenthusiasm displayed by recent authors in this field. On the other hand, many rare but well established entities are not included. An even more serious drawback for a book aimed at the practising histopathologist is the lack of consideration given to possible differential diagnoses.

In conclusion, this new atlas is unlikely to fulfil the need for a comprehensive, authoritative, and up to date reference text on ovarian neoplasms. It cannot be recommended as a bench book for the reporting room.

\section{Notices}

\section{Postgraduate course: \\ Current concepts in surgical pathology}

November 14-18 1994

\section{Massachusetts General Hospital,} Harvard Medical School

This course is designed for pathologists at resident and practitioner levels. It will provide an in-depth review of diagnostic surgical pathology with emphasis on morphological features, newly recognised entities, and new techniques, presented by the faculty of the Department of Pathology, Massachusetts General Hospital. Instruction will be primarily by lecture, but will also include discussion periods. Each participant will receive a comprehensive course syllabus.

The course has category 1 accreditation for about 35 hours CME credit by the American Medical Association. The fee for the course is $\$ 785.00$ (residents and fellows $\$ 575 \cdot 00$ ).

For further information contact: Department of Continuing Education, Harvard Medical School, 25 Shattuck Street, Boston, MA 02115 USA (Tel: 0101 (617) 432 1525).

\section{Update on Cerebrovascular Pathology}

Thursday 8 December 1994 (one-day) to be held at The Royal College of Pathologists, 2 Carlton House Terrace, London SW1Y 5AF.

The meeting is open to members and non-members of the College. Further details and application forms can be obtained from the Scientific Meetings Officer, RCPath, 2 Carlton House Terrace, London SW1Y 5AF (Tel: 0719305862 ext: 24/26).

\section{Cytopathology for histopathologists} Northwick Park Hospital

30 January-3 February 1995

This is an intensive course in cytopathology suitable for candidates preparing for the MRCPath examination in histopathology, and for established histopathologists requiring revision. It is given by the Department of Cellular Pathology, Northwick Park Hospital (Dr Elizabeth A Hudson) and the Department of Cytopathology, St Mary's Hospital Medical School, University of London (Professor Dulcie Coleman).

The programme will consist of lectures, microscopy sessions, and discussions. Topics will include cytopathology of the cervix, urine, the respiratory tract, serous effusions and fine needle aspiration cytology of breast and other sites. The course is limited to 30 participants. The course fee is $£ 300$ excluding accommodation.

Applications and enquiries should be made to: Dr Elizabeth Hudson, Department of Cellular Pathology, Northwick Park Hospital, Harrow, Middlesex HA1 3UJ (Tel: 081-869 3312).

\section{Corrections}

F Clin Pathol 1994;47:205-8; Tillyer et al. The title of the correspondence should read "zinc protoporphyrin assays in patients with $a$ and $\beta$ thalassaemia trait." The title at present implies that zinc assays were performed which was not the case.

In paragraph 2 , the second sentence should read ". . . not only were the drugs causing substantial interference extremely unlikely in the outpatient and general practice population we studied, ...". Paragraph 3 second sentence should read "...Paul and Brumfitt's is $15 \mu \mathrm{mol} / \mathrm{mol}$ haem lower."

DR ML TILLYER

Estimation of haemoglobin concentrations using spectrophotometric tests. $\mathcal{f}$ Clin Pathol 1994;47:681.

The name of the author was given incorrectly as J Larner rather than AJ Larner. ANDREW J LARNER

f Clin Pathol 1993;46:1116-9. (Darjee R, Gibb AP. Serological Investigation into the association between Streptococcus bovis and colonic cancer.) The methods section refers to "NCTC10449 (Enterococcus fecalis), but this should read ATCC19433 (Enterococcus fecalis). NCTC10449 is in fact the reference number of the type strain of $S$ mutans.

AP GIBB

Increased pentane and carbon disulfide in the breath of patients with schizophrenia f Clin Pathol 1993;46:861-4. The concentrations of pentane and carbon disulfide were reported incorrectly. All values of pentane should be multiplied $\times 50$; all values of carbon disulfide $\times 0.05$. The statistical analyses and conclusions of the paper are not affected by these corrections.

MICHAEL PHILLIPS

Chu CM, Liaw YF. Coexpression of intercellular adhesion molecules and class I major histocompatibility compression antigens on hepatocyte membrane in chronic viral hepatitis. I Clin Pathol 1993;46: 1004-8. The correct version of fig $2 \mathrm{D}$ is reproduced below.

CHIA-MING CHU

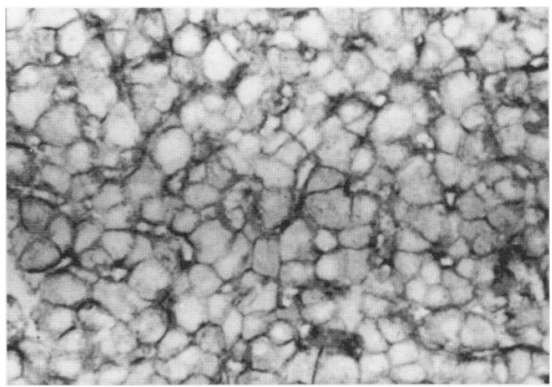

